\title{
"Listen to These Speakers": Swedish Hi-Fi Enthusiasts, Gender, and Listening
}

\author{
Sara Jansson \\ University of Gothenburg, Department of Cultural Sciences \\ sara.jansson@musicology.gu.se
}

\begin{abstract}
The purpose of this article is to explore the practices of Swedish hi-fi enthusiasts from a gender perspective. It builds on the assumption that hi-fi enthusiasts may be understood as participants in a subculture, the structure of which provides a possible explanation to its masculine gender coding. The empirical material is based on interviews with hi-fi enthusiasts, with questions centering on aspects such as music technology, gender, and listening. Two primary aspects of the subculture are discussed: a) the acquisition of subcultural capital (Thornton, 1995), and b) ways of listening.
\end{abstract}

Key words: music technology; gender; high fidelity; listening; subcultural capital.

\section{Introduction}

The empirical material for this article consists of interviews conducted with six hifi enthusiasts aged between 20 and 70 years, five of whom are men.

Two of the hi-fi enthusiasts have hi-fi as a profession (be it to a higher or lower degree): Annie ${ }^{1}$ is in her twenties and has a part-time job at a hi-fi store, and Bob, who is in his seventies, is the owner of a hi-fi store.

In order to find interviewees for whom hi-fi is a hobby rather than a profession, a request was posted on two Swedish hi-fi forums, describing briefly the subject of my PhD thesis in general and this study in particular. So far, interviews have been conducted with the following four hi-fi forum members: Costello, who is in his fifties and a member of forum X; David, who in his forties and a member of forum Y; Elvis, who is in his fifties and a member of forum $\mathrm{Y}$; and Frankie, who is in his late twenties and a member of forum $Y$.

The two forums, referred to in the text as $X$ and $Y$, may be seen as representative of two different attitudes towards music technology in the hi-fi subculture. The members of forum $X$ tend to use technology as a mediator of musical experience: here, technology is used primarily as a tool in order to gain an ultimate musical 
experience; while the members of forum $\mathrm{Y}$ are more likely to literally "listen to the speakers" and be more interested in technology for technology's own sake. Perlman (2004) talks about "golden ears" and "meter readers" as two different subcategories among audiophiles. The former have a similar attitude towards music technology as the members of forum X, while the attitude of the "meter readers" is more of an equivalent to the attitude of the members of forum $Y$ :

Golden-earism privileges the audiophile's intimate, embodied, personal, inalienable, charismatic superiority of aural discrimination. It vests authority in individual experience. By contrast, meter-readism privileges the rationalized, public, impersonal procedures dictated by socially certified experts, and relies on scientific authority (Perlman, 2004, p. 792).

Perlman also notices another difference: the "meter readers" are more likely to be trained in audio engineering than are the "golden ears": "Many of the self-described 'sane', 'scientifically-minded' members of the Audio Society are professional audio engineers, whereas many golden-earists are laymen with respect to engineering" (Perlman, 2004, p. 792).

This article begins with a description and discussion of the term "audiophile", a term commonly used to describe people like those participating in my study. Here, "high fidelity", a concept closely related to the term "audiophile", will also be brought up to discussion. The next section lays its focus on the hi-fi subculture in general, especially looking into the different kinds of subcultural capital, chiefly those of a symbolic and material kind, respectively, that may be acquired by the participants. After that, a more specific aspect of the hi-fi subculture is discussed, namely the masculine gender coding of hi-fi in general. This part of the article takes as its starting point that the connection between masculinity, technology, and "nerdiness" are important factors that contribute to the exclusion of women from the subculture. Thereafter, different ways of listening, including the two ways exemplified by the attitude on the two above-mentioned forums, will be discussed to some extent, although the main aspect brought up to discussion here is what seems to be a common assumption in the hi-fi subculture, namely that women have better hearing than men but tend to be uninterested in music technology. Before the conclusion, a few examples drawn from sources other than my main empirical ones, printed media, will be given in order to demonstrate that the masculinisation of hi-fi is an ongoing process which operates on, and permeates many levels of, the hi-fi subculture.

\section{Audiophiles}

The valuing of accurate reproduction - fidelity to the original - as a supreme audio virtue dates from the earliest days of the phonograph, but it is upheld most vigorously by audiophiles. They hold quite explicitly not only that the standard by which all audio equipment is judged is accuracy, but that the touchstone of accuracy is the sound of live music (Perlman, 2004, p. 789).

Even the most perfect reproduction of a work of art is lacking in one element: its presence in time and space, its unique existence at the place where it happens to be (Benjamin, 1968, p. 220). 
Initially the word "audiophile" was used synonymously with "hi-fi enthusiast" to describe the interviewees. After asking them to describe what they found to be typical characteristics of audiophiles, however, it became evident that many of these descriptions give a rather negative image of audiophiles: they are described as antisocial, having one-track minds, and being absorbed in matters of technological reproduction. The worst kind of audiophiles are understood by one of the interviewees to be more concerned about sound than about music, and to prioritize technology over musical experience. One of the people interviewed also refers to audiophilia as an abnormal interest. Among the more positive descriptions are that they are frequent concert-goers, listen to music a lot, and have a strong interest in music as well as a reasonably strong interest in technology. They are also described by one of the interviewees as wanting the sound to be "realistic".

"Realistic" sound is a term closely related to high fidelity. Much can be said about this complex term, but a longer discussion of high fidelity discourse falls outside the scope of this article. What should be said about high fidelity, however, is that even though the meaning of the term is relatively clear: "truth to the original", it is far from clear what is meant by the "original" (or "truth", for that matter). In the interviews conducted so far, the subject was only touched upon, but one of the interviewees mentions that for him, it is the live performances that are the originals to which the sound-reproduction technologies should be true. Another interviewee describes high fidelity as creating the illusion that the musicians are standing in front of you: "It is when you sit down and listen and you sort of open a gate towards the recorded world, so to speak (...) you're sitting there and then you have the orchestra or musicians in front of you" (David). ${ }^{2}$ This kind of experience is similar to what is indicated by Walter Benjamin's concept of aura (Benjamin, 1968), and is a common one in hi-fi discourse. Here, high fidelity is understood as being able to transcend space and time, enabling the listener to experience the illusion of sharing both time and space (physical and auditive) with the musicians.

Irrespective of whether it is the live concert or the recorded performance that is seen as constituting the original, it is far from clear what is meant by the original musical/sound experience. Is it the way the music sounds when standing in front of the mixing desk at a live show or is it the way the musicians hear themselves on stage, for instance through the stage monitors? (And, if the answer is the latter, through which of the monitors can one hear the "true", "original", sound?) Similar questions may be asked about the recorded performance's truth to the original: is it true to the original if it sounds equal to listening to the recording musicians through the audio engineer's studio monitors and, if so, is it before or after effects are added? Is it at all possible to talk about an "original" sound prior to the final mixing and mastering? Is the usage of different types of microphones and amplifiers that colour the sound in various ways considered to affect or distort the "originality" of the recording? ${ }^{3}$

Annie, Bob, and Frankie do not refer to themselves as audiophiles. Frankie also says he has never used the word. Costello sometimes refers to himself as an audiophile but is careful to point out that for him, music is always more important than technology. David does not describe himself as an audiophile but believes that his colleagues might. Elvis refers to himself as an audiophile but points out that he is not among the anti-social ones.

The negative image of audiophiles, even among those who would describe themselves as ones, described above has led to my decision to talk about hi-fi enthusiasts instead of audiophiles. The former is also a more inclusive term. In their 
article on Japanese audiophiles, Hosokawa and Hideaki (2008) show that this view is present among their interviewees as well:

Their denial suggest the negative stereotype of audiophiles prevailing even among them: exhibitionists who waste money without musical sensibility or care for the equipment (typified by the high-end users featured in the audio magazines) (Hosokawa and Hideaki, 2008, p. 40).

\section{Acquisition of subcultural capital}

Subcultural capital confers status on its owner in the eyes of the relevant beholder (Thornton, 1995, p. 11).

The term subcultural capital was coined by Sarah Thornton, and she draws on Bourdieu's notion of cultural capital. In short, subcultural capital can be described as that which grants one status in a certain community but not necessarily in society at large.

In this study, the kinds of subcultural capital noticed in the hi-fi subculture may be roughly divided into two, more or less intersecting, categories: symbolic and material. To a large extent, symbolic capital has to do with what, or whom, one knows. The material types of capital, on the other hand, have more to do with acquiring artefacts and surrounding oneself with things.

Starting with the symbolic category of capital in the hi-fi subculture, knowledge enables one to be the person other people turn to for advice regarding hi-fi. It also includes adopting a mentor-like role. Social capital also belongs to the symbolic category since it has to do with whom one knows (cf. Thornton, 1995, pp. 10 f.). Knowing the right people might, for instance, enable one to become a member of more or less secret hi-fi societies, which also seems to be a way to acquire subcultural capital.

In the material category of capital equipment can be found. This includes not only state-of-the-art hi-fi equipment, but also peripheral equipment such as records. For instance, it seems that having a large record collection bestows subcultural capital upon the owner. Economic capital is also of the material kind and has to do with how much money one is able to spend on hi-fi.

There are also occasions when these two categories of capital intertwine, most notably in the case of auditive and physical space. While physical space has to do with how much space the equipment itself is allowed to take up in one's home, auditive space has to do with how loud one is allowed to play without disturbing neighbours and family. In both cases, that is, one has to have both material resources (e.g. being able to own a house or affording to sound-proof one's apartment) and symbolic resources (e.g. a family, partner, or roommate that accepts and understands one's hobby). Time can also be seen as a hybrid of material and symbolic capital, since it has to do with the amount of time one is able to, or chooses to, devote to one's hi-fi hobby: the more time spent on hi-fi, the higher amount of capital one seems to acquire. In order to be able to spend time on a hobby, one needs to have the material resources to do so.

The acquisition of symbolic capital can facilitate the acquisition of material capital and vice versa. For instance, having enough knowledge of hi-fi, technology, and electronics means being able to build one's own equipment, and having the money to buy high-end equipment means there's a larger likelihood of being accepted into narrow hi-fi circles, i.e. acquiring social capital. 


\section{Hi-fi and gender}

(...) until recently it hasn't been, it hasn't been OK for girls to try to find their way into, like, the wonderful world of nerdery. It has been completely legit with (...) shopping nerdery and shoe- and handbag nerdery (...). But taking an interest in...quirky cultural phenomena, à la (...) Ghost World (...) is a bit, like, unheard of (...) I don't think it has been a...it hasn't been an eligible path. You have sort of not looked at that as an option. (Frankie)

When the interviewees were asked to estimate the percentage of hi-fi enthusiasts that are women, their answers ranged from not knowing of anyone up to less than $10 \%$. When asked to estimate the percentage of audiophiles that are women their answers ranged from $0 \%$ up to $1,5 \%$ or "a small percentage" (Annie) at the highest. Even though the numbers are low on both sides, the interviewees seem to believe that the percentage of females are lower among audiophiles than among hi-fi enthusiasts. This might be because the term audiophile suggests someone with a more specialized interest.

When asked about the connection between hi-fi and masculinity the interviewees explained the masculine gender coding of the hi-fi subculture using two different kinds of arguments.

The first argument points to gendered structures in society in general. These structures tend to make it more difficult for women to take an interest in hi-fi in the first place. Women have, for instance, had fewer possibilities to gain access to the social circles where an interest in hi-fi is being cultivated. Also, all of the people interviewed agreed that there is a connection between hi-fi and masculinity. Given this connection, one might talk about the exscription (cf. Walser, 1993) of women from the hi-fi subculture. For instance, women are less visible than men both on hi-fi forums and in hifi stores, and hi-fi magazines appear to have a male target audience (cf. Keightley, 1996; Björnberg, 2009). In general, the hobby is regarded as a male one, and the difficulty for women interested in hi-fi to find other women who share their interest as well as the difficulty of attending hi-fi get-togethers as a sole woman were also brought up as restraining factors. Also, one of the people interviewed discussed how nerdiness ${ }^{4}$ is understood as a masculine trait and how "a slightly autistic interest in technology (...) has not been OK for girls [to show] until now" (Frankie). In her articles on the performance of identity on an online forum, Kendall (1999; 2000) discusses gendered aspects of the nerd identity, including its relationship to hegemonic masculinity. Like Frankie, Kendall also notices the connection between nerdiness and masculinity: "(...) nerds are presumed male, as evidenced by the term nerdette. This term, like the use of the phrase 'lady doctor', defines the normative case of nerd as not female". (Kendall, 2000 , p. 266. Emphasis in original). Kendall also explores the identity of the nerd in relation to R.W. Connell's concept of hegemonic masculinity (Connell, 1995). Drawing on Antonio Gramsci's notion of hegemony, hegemonic masculinity is described by Connell as

(...) the configuration of gender practice which embodies the currently accepted answer to the problem of the legitimacy of patriarchy, which guarantees (or is taken to guarantee) the dominant position of men and the subordination of women (Connell, 1995, p. 77).

Connell also points out that what is perceived as hegemonic masculinity changes over time: "'Hegemonic masculinity' is not a fixed character type, always and everywhere the same. It is, rather, the masculinity that occupies the hegemonic position in a given 
pattern of gender relations, a position always contestable" (Connell, 1995, p. 76). According to Kendall,

The nerd stereotype includes aspects of both hypermasculinity (intellect, rejection of sartorial display, lack of "feminine" social and relational skills) and perceived feminization (lack of sports ability, small body size, lack of sexual relationships with women) (Kendall, 1999, p. 356).

In spite of it being somewhat associated with femininity, Kendall points out how the nerd identity is perceived as less compatible with women than with men: "Nerdism in both men and women is held to decrease sexual attractiveness, but in men this is compensated by the relative masculine values attached to intelligence and computer skills". (Kendall, 2000, p. 265). The connection between technological competence, masculinity, and nerdiness, then, may be understood as obstructing women's participation in the hi-fi subculture.

The second argument concerns lack of interest, and is based on the conception that women in general tend to be uninterested in technology. One of the persons interviewed believes that this lack of interest might be explained by biological differences between women and men. The interviewees who use this kind of argument mention the strong emphasis on technology in the hi-fi subculture as an explaining factor for women's relative absence in the subculture. For instance, a common belief in the subculture seems to be that women are more interested in designed hi-fi (presumably because those artefacts are not only about technology). One of the interviewees mentioned an expression used to describe products like these, W.A.F., which is short for Wife Acceptance Factor. The W.A.F. is a fictive measurement of how approving women are going to be of the technology in question. Also, a comment by one of the people interviewed had to do with hi-fi being a time- and money consuming interest which, if gained access to, does not lead to a respected position in society in general:

(...) I think that it...it hasn't been a stronghold worth assaulting. (...) In (...) the boardroom, there is, like, money, power, respect (...). But devoting a large amount of one's time to become a...respected audiophile (...) there is no honour and glory in that (...). (Frankie)

(...) it builds on a sort of, a type of interest that a boy can have. And that nobody reacts to that boy having (...) because it is completely normal. But, like, a girl hasn't really been allowed to have that kind of interest, to, like, be nerding away, really. To become that detached. (Frankie)

In a way, Frankie seems to indicate that women are more pragmatic than men since they do not waste their time and money on something that only enables one to acquire subcultural capital, not capital in society at large. However, he also identifies this as having to do with gendered structures. For instance, he suggests that it is perceived as more acceptable for men than for women to cultivate interests that demand a certain amount of "nerdiness" of its practitioner.

\section{Different ways of listening}

(...) women are just as interested in music as men are (...) perhaps men are more active. (Costello)

(...) many women (...) listen to the perfect result, so to speak. And at the same time they hear the music. (Bob) 
Some examples of the different ways of listening mentioned by the interviewees are the following:

- Concentrated/active listening. Ideal. High level of subcultural capital.

- Listening exclusively to the music, ignoring the sound.

- Listening to the sound.

- Listening to how the music is produced.

- Listening to the music's structure.

- Portable/freestyle listening.

- Background/passive listening (also referred to as "not listening"). Low level of subcultural capital.

It should be mentioned here that the differences between these ways of listening are by no means obvious. Rather, they intertwine in the sense that more than one way of listening can be adopted at the same time.

Concentrated or active listening, preferably in solitude at home, seems to be an ideal form of listening, and it also seems to bestow a high level of subcultural capital upon the listener. One of the people interviewed was in the process of building his own listening room and another one was dreaming of having a listening room of his own.

Background or passive listening, described by one of the interviewees as not listening at all, seems to confer the lowest level of subcultural capital on the listener.

Of the six people that I have interviewed, three, Annie, Costello, and Elvis, told me they always listen to the music first. This is similar to the attitude of the members of forum X, who view music technology as a tool used to obtain a musical experience.

While most if not all of the interviewees were careful to point out how music always comes first, there are some who literally listen to the speakers at times. Frankie told me that since he started to build his own pair of speakers, he always listens to the speakers first; Bob had to stop using a pair of speakers since the sound quality was too good; and David sometimes uses records to evaluate his equipment. This is similar to the "listen to the speakers" attitude that can be found on forum Y.

When conducting research for this study, I spent a lot of time on hi-fi forums as well as reading hi-fi magazines. This was where I first came across the assumption that women have better hearing than men but tend to be uninterested in music technology. That is, there seems to be a general understanding that the reason why few women become hi-fi enthusiasts, even though they are often regarded as having better hearing than men, is because they tend to take little or no interest in technology. It is notable that Annie, being the only woman, is the only one of the interviewees who explicitly disagrees with this statement, and she is also the only one who has not heard of this conception before. The other five agree with this statement for two main reasons.

The first reason is that there seems to be a connection between masculinity and technology in general. One of the interviewees made a comparison with cars: even though anyone can drive a car, men tend to be the ones who change tires. Since men in general are more interested in technology, this is supposed to explain women's lack of interest in music technology.

The second reason is that an interest in technology seems to affect the way one listens. Some of the interviewees seem to believe that since women aren't as interested in music technology or in what component performs which function, they tend to listen in 
a more neutral way: "that you have an interest beyond the (...) components that enables you to listen in a more uncoloured manner" (Frankie). Here, technology is being described as affecting one's expectations, and it is also seen as easier for someone who is uninterested in technology to listen to the music played through a hi-fi in a more objective manner.

\section{Hi-fi and gender in printed media}

Printed media also contribute to the masculine gender coding of the hi-fi subculture. In order to broaden the perspective, examples of how printed media help to construct the hi-fi subculture as masculine will be given. These examples centre on two themes: the tendency to compare women with music-technological artefacts, and stereotypical representations of gender in magazines. ${ }^{5}$ Furthermore, the examples range from the 1920s to the twenty-first century, and thus suggest that these gendered themes are both prevalent and firmly rooted in music-technological discourses.

The tendency to compare women with music technology is reflected in these two quotes from a Swedish hi-fi magazine:

It is just as difficult to choose speakers as it is to choose a girl, the one who looks good on the outside is not always as pretty on the inside and still, in both cases it ought to be the latter that should matter the most (Stereo-Hifi 2/1970, p. 12). ${ }^{6}$

To choose a pair of speakers is difficult; what sounded delightful in the store can in the long run turn out to be a nerve-racking nuance. Speakers are like the womenfolk; those that last the best in the long run are those with the least spectacular qualities (Hifi\&Musik 1/1997, p. 14.).

The quotes above are almost identical even though the second one was published almost thirty years after the first. These are just two of many examples of how women are being used as metaphors for artefacts of music technology in hi-fi magazines as well as in the hi-fi subculture at large. Examples of this can be found prior to the establishment of the concept "high fidelity" as well. In 1928, for instance, the following humorous fictive discussion between two men was reproduced in the magazine Radiolyssnaren (The Radio Listener):

Mr Andersson (to his neighbour, Mr Pettersson): "Would you please turn off that blaring speaker a moment?" Mr Pettersson: "I don't have a speaker, it was just my wife who sang a little tune" (Radiolyssnaren $31 / 1928$ p. 3.).

Unlike the other two examples, however, this is not an explicit metaphor. Rather, the fact that Mr Andersson mistake Mr Pettersson's wife's song for the sound coming out of a speaker can be interpreted in several ways: having to listen to unwanted singing can be just as annoying as having to listen to unwanted sound coming out of a neighbour's speaker; Mrs Pettersson is such a bad singer that her song can be confused with the imperfect quality of technologically reproduced sound in the 1920s; or women are as uncontrollable and unpredictable as the neighbour's sound-reproduction technology. This propensity to liken women to technology has been noted elsewhere. Hosokawa and Hideaki (2008, p. 41) describes an "audio enthusiast" who "(...) nicknamed his Brunswick hand-cranked player 'the Princess Madrid' (Madrid was the brand name) and every year he celebrated the date of her 'wedding' (purchase) (...) Thus he deified and feminized the machine (...)". Théberge (1997, pp. 124 f.) notices a similar trend in 
advertisements in "high technology magazines". See also Keightley (1996); Björnberg (2009).

The second theme, stereotypical representations of gender can be found in these two quotes from an article on audiophiles in the Swedish newspaper Sydsvenskan:

There are quite a lot of audiophiles that are bachelors. This hobby doesn't work with women. It is really strange: a woman knows where her husband is if he is interested in hi-fi. He is in the adjacent room tinkering with his equipment. And besides she gets to listen to wonderful music. (Audiophile interviewed in Swedish newspaper Sydsvenskan 21 January 2006.)

Unfortunately, many have wives. That is a huge problem: the girls only care about furnishing, if the colour of the speakers match. (Hi-fi store owner interviewed in Swedish newspaper Sydsvenskan 21 January 2006.)

These two quotes illustrate the masculine gender coding of the hi-fi subculture in several ways. Hi-fi is described as incompatible with women, a notion which in the first quote constitutes an explanation to why many hi-fi enthusiasts are bachelors. In the second quote, however, women (wives, to be exact) are presented as a problem. Here, wives are seen as obstructing their men's interest in hi-fi by placing too much emphasis on the artefacts' design elements. The understanding of women as more interested in design and men as more interested in technological aspects can be found in the following quote as well:

This should result in a receiver that fulfills heavy demands on frequency stability, distortion and a reception free from interference - and also the ladies' demands for elegance! (Musik och Ljudteknik 4/1965 p. 24.)

Here, women are represented as placing emphasis on the appearance of technology while being indifferent to the technical data considered to enhance the quality of the sound reproduction. Hence, this review of a do-it-yourself kit indicates a view of women as secondary users of technology.

\section{Conclusion}

Gendered aspects of the hi-fi subculture counteract women's participation in the hi-fi subculture on equal terms as men in a number of ways. For instance, stereotypical notions of gender in the subculture result in women tending to be described as uninterested in technology but as having good hearing. Women are also pictured as more interested in the design of, rather than in the technological aspects of, hi-fi equipment. The connection between masculinity and technology in general, and nerdiness being understood as a masculine trait, also combine to counteract women's participation in the subculture. Finally, as shown in the section on printed media, there is also a tendency in hi-fi discourse to compare women with music technology, thereby representing women as objects rather than legitimate users of technology.

The overarching consequence of these attitudes is that the connection between music technology, hi-fi, and masculinity is maintained. This, in turn, contributes to and legitimizes women's exclusion from the subculture. 


\section{Notes}

1. Pseudonyms have been used for all the interviewees.

2. The quotes of the interviewees have been translated from Swedish to English by the author.

3. For more thorough discussions on high fidelity from a historical perspective, see for example Keightley (1996); Sterne (2003); and Björnberg (2009).
4. For a definition of the nerd stereotype, see Kendall (1999, pp. 355 f.; 2000, p. 262).

5 . I will present a more thorough historical account of gender representations in magazines dealing with music technology in my PhD thesis.

6. The quotes from the magazines have been translated from Swedish to English by the author.

\section{Acknowledgements}

I am greatly indebted to all my interviewees for taking their time to participate in this study. I would also like to thank everyone at the IASPM 15th Biennial Conference for inspiring presentations and discussions. Last, but not least, I would like to thank my supervisor, professor Alf Björnberg, for going through several versions of this article with me. His good advice and insightful comments were very useful to me.

\section{References}

Benjamin, Walter. 1968. 'The Work of Art in the Age of Mechanical Reproduction' in Illuminations, Schocken Books, New York, pp. 217-251.

Björnberg, Alf. 2009. 'Learning to Listen to Perfect Sound: Hi-Fi Culture and Changes in Modes of Listening, 1950-80' in D.B. Scott, ed. The Ashgate Research Companion to Popular Musicology, Ashgate, Aldershot.

Connell, R. W. 1995. Masculinities, University of California Press, Berkeley and Los Angeles.

Hifi\&Musik. 1/1997. 'Favorit med fräschör' ('Favourite with Freshness'), pp. 14 f.

Hosokawa, Shuhei; Matsuoka, Hideaki. 2008. 'On the Fetish Character of Sound and the Progression of Technology: Theorizing Japanese Audiophiles' in G. Bloustein; M. Peters; S. Luckman (eds.). Sonic Synergies: Music, Technology, Community, Identity, Ashgate, Aldershot and Burlington, pp. 39- 50.

Keightley, Keir. 1996. "'Turn it Down!” She Shrieked: Gender, Domestic Space, and High Fidelity, 1948-59'. Popular Music, Vol. 15, No. 2, pp. 149-177.

Kendall, Lori. 1999. “The Nerd Within": Mass Media and the Negotiation of Identity Among Computer-Using Men'. The Journal of Men's Studies, Vol. 7, No. 3, pp. 353-369.

Kendall, Lori. 2000. '“Oh No! I'm a Nerd!" Hegemonic Masculinity on an Online Forum'. Gender \& Society, Vol. 14, No. 2, pp. 256-274. 
Musik och Ljudteknik. 4/1965. 'Vi har provat Fisher KM-60' ('We've tried out Fisher KM60'), pp. 21-24.

Perlman, Marc. 2004. 'Golden Ears and Meter Readers: The Contest for Epistemic Authority in Audiophilia'. Social Studies of Science, Vol. 34, No. 5, pp. 783-807.

Radiolyssnaren. 31/1928. 'Goda vänner, trogna grannar...' ('Good Friends, Loyal Neighbours...'), p. 3.

Stereo-Hifi. 2/1970. 'Högtalare i alla former' ('Speakers in all Forms'), pp. 12-16.

Sterne, Jonathan. 2003. The audible past: Cultural origins of sound reproduction, Duke University Press, Durham and London.

Sydsvenskan. 2006. 'Audiofiler: En berättelse om dem som ständigt söker det perfekta ljudet' ('Audiophiles: A Story about Those Always in Search of the Perfect Sound'), 21 January.

Théberge, Paul. 1997. Any sound you can imagine: Making music/consuming technology, Wesleyan University Press, Hanover and London.

Thornton, Sarah. 1995. Club Cultures: Music, Media, and Subcultural Capital, Polity Press, London.

Walser, Robert. 1993. Running with the devil: Power, gender, and madness in heavy metal music, Wesleyan University Press, Hanover. 